\title{
AS REPRESENTAÇÕES DAS "NAÇÕES" BRASILEIRAS NOS ENREDOS DAS ESCOLAS DE SAMBA DO RIO DE JANEIRO
}

\author{
Antonio Henrique de Castilho Gomes ${ }^{1}$
}

\begin{abstract}
Resumo: O carnaval carioca tem sido ao longo de todo o século XX e deste início de século XXI, uma das manifestações culturais mais importantes do cenário brasileiro. Ao longo de sua história, uma instituição surgida na virada dos anos de 1920 para os anos de 1930, foi se tornando protagonista: a escola de samba. Herdeiras diretas dos blocos carnavalescos, dos ranchos e das grandes sociedades, as escolas de samba em um movimento antropofágico, foram devorando e reprocessando elementos oriundos destas outras manifestações culturais, vinculados ao carnaval, quer populares ou não. Nosso objetivo, pretensioso como sempre está focado no enredo, não na realização de um tratado acerca da História do enredo ou do seu significado e muito menos de como ele é pensado e desenvolvido. O que pretendemos de fato é entender como a ideia de nação brasileira (com todos os riscos que esta ideia carrega) foi representada nos enredos das escolas de samba do Rio de Janeiro, e como tais representações podem nos auxiliar a compreender os deslocamentos que tais ideias sofreram ao longo dos séculos XX e XXI.
\end{abstract}

Palavras-chave: Nação. Representação. Samba.

The representations of brazilian nations in the subjects of the schools of samba of Rio de Janeiro

Astract: The Carioca carnival has been one of the most important cultural manifestations in Brazil throughout the twentieth century and still remains in the beginning of the twenty first century. All the way through its history, an institution that emerged around the 1920sand 1930s became its protagonist: The Samba school. Direct heirs of the carnival blocks, the ranchos and the great societies, the Samba schools, in an anthropophagic movement, have been devouring and reprocessing elements originated in other cultural manifestations, and have linked them to carnival, whether are them popular or not. Our goal, as pretentious as it is, focus the analysis on the plot, that is not our aim to make a treatise on the history of the plot or its meaning, not even on how it is thought and developed. What we really want to do is to understand how the idea of a Brazilian nation (with all the risks that this idea carries) was represented in the plots of the Samba schools of Rio de Janeiro, and how such representations can help us understand the displacements that such ideas suffered from the 20th to the 21 st centuries.

Keywords: Nation. Representation. Samba.

\section{A ideia de representação na narrativa carnavalesca}

O enredo é uma apropriação antropofágica que as escolas de samba realizaram no

\footnotetext{
${ }^{1}$ Professor Doutor, na Escola SESC de Ensino Médio. Rio de Janeiro, RJ. Brasil.
} 


\section{Universidade do Extremo Sul Catarinense \\ Revista Ibero-Americana de Humanidades, Ciências e \\ Educação \\ unesc

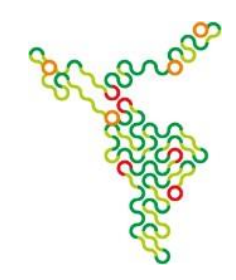

início da sua história. A ideia de apresentar uma narrativa ao longo do desfile nasce em outras manifestações importantes da festa do carnaval do Rio de janeiro, os Ranchos e as Grandes Sociedades. Inicialmente as escolas apresentavam esta narrativa através apenas das suas fantasias e de suas alegorias. Só mais tarde é que o canto se associará a estes elementos para então compor uma narrativa expressa na música, na dança e nos aspectos plásticos do desfile. Desta forma, o enredo passa a ser elemento visceral da escola de samba.

[...] a peça fundamental que desencadeia o complexo macro texto audiovisual do desfile das escolas de samba chama-se enredo. O enredo, que é o fio condutor do todo o desenvolvimento do desfile das escolas de samba [.... A definição do enredo é o primeiro passo para a elaboração de todos os itens do desfile. (FARIAS, 2007, p.13)

Mas como o enredo se faz compreender? Segundo o escritor Júlio César Farias o enredo é uma forma específica das linguagens de cultura popular, uma "linguagem carnavalesca, cujo conteúdo reúne diversas linguagens numa só” (Op. Cit. p 13). Estão presentes na estrutura narrativa do enredo as mais variadas expressões artísticas: esculturas, pinturas, indumentária, música, canto, dança, literatura e teatro, coadunadas para dar significado a sua proposta de enredo. Entretanto, neste fenômeno cultural a ideia de representação é superada por uma espécie de representação da representação, ou se preferirmos pela carnavalização da ideia. Em um universo complexo de traduções, para o conceito de representação, podemos afirmar que a ideia consiste em construir uma imagem que, dentro de um contexto, ocupa o lugar da realidade que se quer apresentar. Entretanto, esta imagem não pode ser compreendida como a realidade que representa, ela nunca será uma expressão fidedigna, verossímil da realidade.

Esta também não é a proposta de uma escola de samba, ela precisa superar esta tese e reconfigurar a mensagem em uma representação de uma representação. Talvez o maior exemplo que se possa trazer para compreender este aspecto fundamental da linguagem carnavalesca sejam duas alegorias de escolas diferentes apresentadas no carnaval de 2011. O GRES Acadêmicos do Salgueiro naquele ano apresentava o enredo "O Rio no cinema" (Renato Lage) e trazia em um dos seus carros alegórico uma estátua imensa do King Kong, personagem de um famoso filme homônimo (1933, 1976 e 2005). Entretanto, o King Kong não estava no Empire State Building, ou no World Trade Center, estava com o relógio da central do Brasil no colo. O carnavalesco ressignificou, carnavalizou, um dos mais celebrados personagens da ficção cinematográfica. No mesmo ano o GRES Unido da Tijuca apresentava o enredo "Esta noite levarei sua alma" (Paulo Barros), que brincava com histórias que causam medo e tensão. Em um de seus carros alegóricos, o carnavalesco reproduziu, de forma excepcional, uma antológica cena da franquia Indiana Jones. 


\title{
Universidade do Extremo Sul Catarinense Revista Ibero-Americana de Humanidades, Ciências e Educação

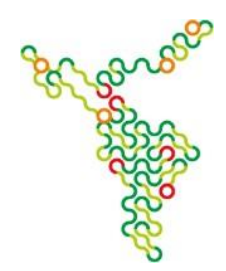

Entretanto, Paulo Barros buscou a perfeição da reprodução da cena, e de fato conseguiu, contudo, esta perfeição pode nos levar a ideia de que a alegoria não cumpriu o papel de ressignificação, ou carnavalização, que se espera. O que pretendemos ressaltar é que a ressignificação do carro da Acadêmicos do Salgueiro expressa com muito mais clareza a tese de que o enredo da escola de samba não representa apenas uma ideia, ele a ressignifica, carnavaliza, realiza a representação da representação.

\begin{abstract}
Agora quero voltar para a metalinguagem, quando você fala de representação da representação. Tem um desfile do João Trinta que é o Orfeu (Orfeu. O negro do Carnaval, GRES Unidos do Viradouro, 1998). O Orfeu é pura metalinguagem. Orfeu mora numa favela, a escola de Orfeu monta um desfile sobre o Carnaval e a Viradouro do João Trinta, traz o Orfeu do seu desfile para o desfile. É a metalinguagem da metalinguagem. Acho que este é o enredo mais maluco da representação da representação. Pega uma representação mítica de que a comunidade de Orfeu traz para o carnaval e aí funde isso e você não sabe se é o olho do João ou do Orfeu. Se são os dois ao mesmo tempo, ou se é um terceiro olho.
\end{abstract}

A narrativa do enredo de uma escola de samba procura, então, levar o espectador a uma leitura sobre o tema proposto onde se misturam muitos olhares e muitas vozes, como em uma proposta polifônica, onde nem sempre o que está representado é uma pura e simples representação daquela realidade exposta. James Clifford desenvolve um conjunto de teses interpretativas que conferem as vozes que emanam das comunidades igual peso às vozes que as interpretam. Constituindo assim a proposta de que há uma polifonia discursiva nestas falas. Transpondo estas teses para a análise da narrativa do enredo de uma escola de samba, nos parece satisfatório compreender que há no enredo um conjunto de vozes que se faz ouvir ao mesmo tempo e que garante que o que se apresenta não seja uma mera representação de uma dada realidade, mas sim uma ruptura com esta lógica produzindo um efeito carnavalizante, onde a proposta a ser apresentada aparece com uma representação de uma representação, ou como o próprio Milton Cunha nos revela "é um terceiro olho". Neste contexto, talvez as imagens do King Kong e o enredo "Orfeu: O negro do Carnaval" nos sirvam para compreendermos melhor a dimensão deste elemento discursivo contextualizado na cultura carnavalesca.

A ideia de nação nos enredos das escolas de samba do Rio de Janeiro

Quando, pela primeira vez, alguma escola de samba propôs em seu enredo narrar o Brasil, traduzir na sua narrativa a ideia de nação brasileira? A priori esta é uma resposta relativamente fácil de responder. Entretanto, nosso objeto não é buscar uma data ou um período em que este fenômeno teria acontecido. Poderíamos nos perguntar também quantos enredos abordaram, direta ou indiretamente, temáticas brasileiras. O pesquisador Júlio César Farias, em sua obra "O enredo de escola de samba" faz um levantamento interessante. Tomando por alto sua pesquisa, perceberemos um número incontável destes 


\section{Universidade do Extremo Sul Catarinense \\ Revista Ibero-Americana de Humanidades, Ciências e \\ Educação \\ unesc

enredos.

Entretanto, o que nos despertou a curiosidade pesquisadora não foi o número, mas a percepção de que a ideia, ou conceito, de brasilidade aparece nos enredos das escolas de samba de formas variadas. Neste cenário de variedades, podemos encontrar pelo menos duas formas de "representações" do conceito de nação apresentadas pelas escolas de samba do Rio de Janeiro: um conceito de nação narrado a partir de grandes temas nacionais, transmitindo uma ideia de que há um Brasil uníssono, representado, ou percebido, por temas, eventos, cultura e até mesmo personagens, que transcendem a ideia do regional, e se transfiguram em elementos supranacionais. E outro em que este caráter supranacional que consolidava a ideia de nação, foi sendo progressivamente substituído por signos muito mais regionalizados. A pergunta que deveremos responder seria então: Quais motivos, num determinado momento, levam a construção de uma narrativa da nação brasileira que adota um modelo simbólico, e em outro momento tais símbolos são substituídos por outra modalidade?

Primeiramente, vamos compreender como e porque os temas nacionais dominam as narrativas do enredo das escolas de samba do Rio de Janeiro no início de sua História. Em 1938 a primeira associação de escolas de samba sugeria em seu regulamento o uso dos temas nacionais, na década seguinte (1947) o que era sugestão tornava-se obrigatoriedade. Assim, ao contrário do que se possa pensar tal temática não foi uma imposição do Departamento de Imprensa e Propaganda do governo Vargas (DIP). É claro que a sugestão de 1937, pode ter sido influenciada pelo DIP, mas colocar as escolas de samba no lugar da fragilidade é um erro. A questão central é que tal atitude vai ao encontro do projeto de afirmação e reconhecimento das escolas de samba, liderado em grande parte pela figura de Paulo da Portela. É uma das estratégias utilizadas por tais agremiações para se tornarem hegemônicas no cenário cultural do carnaval carioca. Neste sentido o uso das temáticas nacionais iam ao encontro da política do Estado Varguista, que desde seu início consolidava uma nova perspectiva simbólica que ajudavam a construir um novo ideário de identidades nacionais. Tal perspectiva atravessa duas questões importantes: romper com uma tradição inventada de que o Brasil se consolidara enquanto nação a partir de

\footnotetext{
${ }^{2}$ Pomos aqui a expressão entre aspas pelos argumentos expostos anteriormente, em que afirmamos que a narrativa carnavalesca realiza uma espécie de representação da representação.
} 


\section{Universidade do Extremo Sul Catarinense \\ Revista Ibero-Americana de Humanidades, Ciências e \\ Educação \\ unesc

uma hegemonia branca europeizada, vendo um possível caráter híbrido como um elemento de fracasso para este projeto, substituindo-a pela crença que a singularidade brasileira estaria expressa justamente no seu caráter mestiço (ou híbrido). A outra questão está na necessidade de se romper com a estrutura de poder que se sustentava numa troca de favores entre o governo central e os governos estaduais. Desde o início de seu governo, em 1930, Vargas inicia um processo de ruptura destas duas questões, reconfigurando o aparelho simbólico do ideário nacional e as relações de poder, centralizando mais as decisões em âmbito nacional. Destes aspectos nos interessa a reconstrução simbólica da ideia de nação que, de certa forma ia ao encontro do projeto de reconhecimento e construção de hegemonia próprio das escolas de samba. Cremos que houve (e ainda há), uma estratégia malandra destas agremiações que são usadas pelo Estado para afirmarem seu novo projeto de nação, mas que ao mesmo tempo se utilizam deste mesmo Estado para assumirem o papel de protagonismo no carnaval carioca e se configurarem em espaço de fala das categorias subalternas que estão nas bases destas agremiações (compositores, ritmistas, passistas etc.).Desta forma, o samba passa a ser visto como símbolo desta mestiçagem (ou hibridismo) e vai pouco a pouco, deixando de ser objeto de perseguição por parte das autoridades policias do Estado e se transformando no símbolo maior desta brasilidade mestiça. A partir daí, construía-se mais uma tradição: a de que brasileiro já nasce gostando de samba e esta nova novidade ajuda a consolidar uma nova perspectiva construída a respeito da ideia de nação brasileira.

[...] invenção do samba como música nacional foi um processo que envolveu
muitos grupos sociais diferentes. O samba não se transformou em música
nacional através dos esforços de um grupo social ou étnico específico, atuando
dentro de um território específico (o 'morro'). Muitos grupos e indivíduos
(negros, ciganos, baianos, cariocas, intelectuais, políticos, folcloristas,
compositores eruditos...) participaram com maior ou menor tenacidade, de sua
'fixação como gênero musical e de sua nacionalização'. Os dois processos não
podem ser separados. Nunca existiu um samba pronto, 'autêntico', depois
transformado em música nacional [...]. (VIANNA, 1965, p.162)

Assim é possível compreender o fenômeno dos enredos supranacionais como elemento simbólico desta dupla função ${ }^{3}$, consolidar a ideia de um Brasil híbrido (ou mestiço, muito embora haja críticas pertinentes a esta expressão), e dotado de uma identidade supranacional (sem que necessariamente os regionalismos desapareçam), e

\footnotetext{
${ }^{3}$ Para maior aprofundamento acerca dos diálogos realizados entre as escolas de samba e o Estado brasileiro, sugiro novamente a leitura da obra "A [re]configuração do discurso do samba".
} 


\section{Universidade do Extremo Sul Catarinense \\ Revista Ibero-Americana de Humanidades, Ciências e \\ Educação \\ unesc

como elemento que consolida a travessia do samba de manifestação perseguida para símbolo maior desta "nova" nação. Entre as décadas de 1930, 1940 e 1950 muitos foram os enredos que narraram a ideia de nação brasileira dentro desta perspectiva, gostaríamos de destacar cinco deles: Carnaval de Guerra, Portela 1943; Motivos Patrióticos, Portela 1945; Tomada de Monte Castelo, depois eu digo; Grito do Ipiranga, Azul e Branco do Salgueiro 1947 e Exaltação a Tiradentes, Império Serrano 1949.

Como explicar agora a ressignificação que os conceitos de nação ou de brasilidade sofrem na narrativa carnavalesca a partir da década de 1990? Urge esclarecer que esta data é uma escolha nossa e que nem de longe deixa de ser esgarçada para anos anteriores ou posteriores. A questão central é de que a narrativa carnavalesca começa a apresentar o Brasil a partir de uma perspectiva mais regionalizada. Os temas supranacionais vão sendo substituídos por temáticas "minimalistas" regionalizadas que constroem variados signos de brasilidade. O que levou a esta ressignificação? Dentro das possibilidades de compreensão escolhemos três caminhos: compreender que a própria forma como se enxerga as representações possíveis de uma ideia de nação sofreram uma transformação nas últimas décadas. Depois apontaremos para uma necessidade oriunda da própria estrutura da narrativa carnavalesca, do enredo e por fim, tentaremos explicar este fenômeno também por conta de uma perspectiva econômica.

As teses mais fecundas sobre análises da ideia de identidade caminham na direção de que no tempo presente, ou na pós-modernidade se preferirmos, a identidade se tornou móvel, formada e transformada continuamente:

Esse processo produz o sujeito pós-moderno, conceptualizado como não tendo uma identidade fixa, essencial ou permanente. A identidade torna-se uma 'celebração móvel': formada e transformada continuamente em relação às formas pelas quais somos representados ou interpelados nos sistemas culturais que nos rodeiam. (HALL, 2005, p. 13)

Dentro desta perspectiva apontada pelos chamados "Estudos Culturais" não seria possível a construção de uma ideia de nação a partir de um conjunto simbólico supranacional. Partindo deste pressuposto, observamos uma multiplicidade significativa de "Brasis" e de "brasileiros" que se reafirmam cotidianamente num universo plural e poli enraizado ${ }^{4}$. Esta nova modalidade de sujeito tornaria minimante contraditório

\footnotetext{
${ }^{4}$ Aproprio-me aqui do conceito de sujeito poli enraizado construído por Edgar Morin em sua obra "Meus demônios".
} 


\section{Universidade do Extremo Sul Catarinense Revista Ibero-Americana de Humanidades, Ciências e Educação \\ unesc

representar o Brasil a partir de uma perspectiva nacionalista, ufanista e acima de tudo monocultural. Desta forma aqueles que concebem a narrativa carnavalesca do enredo, também estariam pensando dentro desta mesma perspectiva. Segundo o carnavalesco Milton Cunha, este fenômeno tem relação com a "cultura da universalização, da pós modernidade, do estilhaço"(CUNHA, entrevista concedida ao autor). Ficando então mais fácil para quem pensa o enredo, concebe-lo a partir do recorte. $\mathrm{O}$ fato é que experimentamos um momento em que os eventos falam mais alto do que suas estruturas ou suas conjunturas. As redes sociais, as possibilidades do tempo real, mesmo que ilusórias, fragmentam conceitos e ideias.

Esses 'entre lugares' fornecem o terreno para a elaboração de estratégias de subjetivação - singular ou coletiva - que dão início aos novos signos de identidade epostos inovadores de colaboração e contestação no ato de definir a própria ideia de sociedade. (BHABHA, 1998, p.20.)

Assim, construir uma comunidade nacional (sempre imaginada) passa ser resultado de diversas tensões manifestadas nas mais diversas narrativas, dentre elas a narrativa carnavalesca, ou se preferirmos nos enredos.

É imaginada porque até os membros da menor nação nunca conhecerão, nunca encontrarão e nunca ouvirão falar da maioria dos outros membros dessa mesma nação, mas, ainda assim, na mente de cada um existe a imagem de sua comunhão. (ANDERSON,1989, p. 27)

Uma das tensões que provocam tal deslocamento das representações da nação nas narrativas carnavalescas é o confronto entre uma ideia globalizante, totalizante de Brasil com as perspectivas locais. Este fenômeno pode ser observado na emergência de determinados movimentos artísticos típicos de uma dada regionalidade dentro dos espaços midiáticos de amplitude nacional. Ora a escola de samba, que historicamente sempre soube dialogar com o contexto no qual esteve inserida, também vai dialogar com estas novas perspectivas construindo sua narrativa acerca da ideia de nação a partir de uma perspectiva mais fragmentada e regionalizada, do que outrora o fazia.

Outra possibilidade, que dialoga intimamente com a que discutimos até agora, está vinculada a estrutura da própria narrativa carnavalesca, que precisou se tornar mais específica, mais

detalhada, por conta de questões que envolvem o universo da própria escola de 


\section{Universidade do Extremo Sul Catarinense \\ Revista Ibero-Americana de Humanidades, Ciências e \\ Educação \\ unesc

samba e de seu objetivo fim: o desfile, a competição. Estas transformações implicarão em mudanças que, dialeticamente, se relacionarão com a forma como a estrutura narrativa carnavalesca representa a ideia de nação. As escolas de samba sempre adotaram uma estratégia malandra, ao longo de sua história, dialogando com o Estado, com diversos segmentos sociais que a ela foram se integrando e com a indústria cultural ou do entretenimento. Este diálogo "obrigou" as escolas de samba produzirem modificações nas suas diversas estruturas. A diminuição do tempo do desfile e o aumento significativo dos componentes obrigou a compactação dos desfiles. Por conta disso, as fantasias passaram a privilegiar ombros e cabeças porque passaram a ser suas partes mais observadas e mais visíveis. A participação, dentro e fora da escola (principalmente na comissão julgadora), de segmentos sociais plurais (uma espécie de transclassismo) fez com que estas buscassem realizar seus desfiles de modo que a compreensão dos mesmos se desse por um público cada vez mais diverso. Estas novas "necessidades" também vão provocar alterações na estrutura narrativa do enredo. Na medida em que a escola foi ressignificando suas estratégias, precisou também reconfigurar a estrutura do enredo, que passou a ser concebido dentro de um esquema muito definido. Desta forma o enredo precisa ser "executado" de forma compreensível, não apenas para o componente ou para a plateia, mas principalmente para o julgador.

Hoje o enredo tem uma estrutura de composição muito fragmentada. Quando a escola escolhe um enredo, um tema, o primeiro passo é definir qual o recorte deste tema. Neste sentido, quando o tema tangencia a ideia de nação, funde-se a fragmentação da proposta com a fragmentação do próprio conceito de nação.

Hoje se está privilegiando o recorte. Os enredos já não são bons ou ruins a priori, eles vão ter bons ou maus recortes. Então, o ângulo de visão que você vai fazer do seu enredo, é o que vai definir se ele é bom ou ruim (...). Para além do recorte, a própria estrutura do desfile organizada, obrigatoriamente em sete eixos, também força a fragmentação. (CUNHA, entrevista concedida ao autor).

Dentro desta perspectiva torna-se óbvio que o conceito de nação também se fragmente. É verdade que as necessidades que levam a ideia de fragmentação do enredo, estão contidas na mesma visão de mundo (discutida anteriormente) que também fragmenta o universo simbólico da nação. Seria inocente de nossa parte acreditar que há um determinismo da estrutura do desfile sobre a forma como a ideia de nação é ressignificada. Entretanto também não seria prudente acreditar no oposto.

Por último é a questão do patrocínio, ou dos enredos patrocinados. Parte destes 


\section{Universidade do Extremo Sul Catarinense \\ Revista Ibero-Americana de Humanidades, Ciências e \\ Educação \\ unesc

enredos patrocinados ilumina regiões, cidades, traços ou manifestações culturais, eventos (históricos ou não), que se transformam em uma espécie de colcha de retalhos que juntos irão constituir uma ideia multiforme de nação: $O$ trabalhador rural, ou a vida simples no campo; o nordestino, o jegue que me carregou (ou o camelo que me derrubou) a farroupilha, as águas de Caxambu, Macapaba e tantos outros aspectos regionalizados vão apresentando uma brasilidade que parte não mais de uma temática supranacional, de um traço comum a qualquer região. A imagem de um Brasil e de um brasileiro é desconstruída e em seu lugar surgem muitos "Brasis" e muitos "brasileiros". Entretanto as origens destes enredos também são dotadas de uma multiplicidade de explicações e de fundamentações que dialogam entre si.

Uma obviamente é o que já estamos discutindo desde o início deste trabalho, que é a ressignificação destes conceitos (Brasil e brasileiro), a outra é meramente econômica. Tais enredos são acompanhados por incentivos financeiros vinculados a uma série de interesses econômicos. Apresentar uma cidade, uma região, um traço cultural de uma dada região, aumenta a possibilidade turística do representado. A amplitude e a internacionalização da transmissão dos desfiles para mais de 150 países, transformam os mesmos em grandes possibilidades de propaganda, não apenas tangentes a atividade turística (dentro e fora do Brasil), mas também ao mundo corporativo. Diversas empresas já patrocinaram enredos que apresentaram aspecto de seus negócios: energia, alimentação, bebida, moda etc., mas porque tornou-se tão importante para uma escola de samba ampliar suas fontes de captação de renda? O tradicional patrocínio do jogo do bicho tão comentado na história das escolas de samba não é mais suficiente? O fato é que, por uma série de fatores, dentre eles a complexidade em toda a estrutura de desfile e a necessidade de certa profissionalização dos processos criativos e construtivos, vem exigindo das escolas um esforço econômico cada vez maior. Seja pelo gasto em carros alegóricos, adereços, fantasias etc, seja no financiamento das chamadas alas da comunidade, os custos das escolas a cada ano tornam-se maiores, e o patrocínio aparece como uma significativa possibilidade de fonte de renda. Alguns pesquisadores desenvolveram uma teoria de que as escolas se constituíram em empresas capitalistas para conseguirem, nos moldes em que se apresenta a estrutura do desfile, realizar seu carnaval. Os trabalhos destes pesquisadores estabelecem as políticas públicas como elemento importante nesta cadeia produtiva, entendendo este aspecto como investimento em 


\section{Universidade do Extremo Sul Catarinense Revista Ibero-Americana de Humanidades, Ciências e Educação \\ unesc

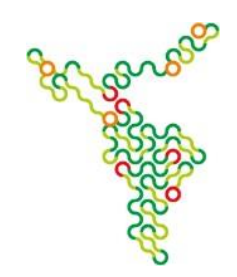

infraestrutura, fomentos e incentivos fiscais. Não é nosso objetivo aqui discutir amplamente este conceito de cadeia produtiva, mesmo sendo de relevância para a compreensão da megaestrutura que cerca a produção do carnaval. Para um aprofundamento maior sugiro aos interessados a leitura completa da pesquisa "Cadeia produtiva da economia do carnaval" de autoria de Luiz Carlos Prestes Filho, Sérgio Cidade, Carlos Saboya Monte, Clarissa Alves, Sidney Limeira, Antonio Alkmin e Pedro Argemiro. Para nós interessa observar a questão dos fomentos ou patrocínio, principalmente no que tange a escolha de enredos motivados por esta demanda. Mas quando teria aparecido no cenário do carnaval carioca a ideia do enredo patrocinado? Segunda a pesquisadora Raquel Valença, em 1985 o Império Serrano teria realizado um enredo sobre a Cerveja, bebida tradicional no universo do sambista. Daí pensou-se a possibilidade de obter alguns recursos com uma dada cervejaria. Mas, ainda segundo a pesquisadora, a Rocinha em 1994 teria tido um enredo patrocinado por uma indústria alimentícia, via Lei Rouanet.

O patrocínio no enredo é possibilitado por uma série de legislatura que garante a quem patrocina vantagens que vão além das vantagens econômicas com a publicidade da marca, da região, da cidade ou do evento narrado por uma determinada escola de samba 5 . A partir destes aparatos legais as escolas de samba começaram a perceber, que o enredo poderia ser uma fonte de renda significativa. A partir desta realidade concreta, começaram a aparecer os chamados enredos patrocinados, em um número cada vez maior de agremiações. Desta forma, algumas prefeituras e governos estaduais, passaram a utilizar o carnaval das escolas de samba do Rio de Janeiro, para se projetarem tanto no cenário nacional quanto no cenário internacional e com isso ampliar potencialmente a atividade turística. Tornou-se então uma marca do carnaval das escolas de samba do Rio de Janeiro, sempre apresentarem no conjunto de seus enredos homenagens a cidades ou estados brasileiros, retomando assim uma lógica regionalizada na representação simbólica da ideia de nação brasileira.

Para concluir e corroborar nossas argumentações, que buscam explicar o

\footnotetext{
${ }^{5}$ Sugiro aqui a leitura dos textos do Pronac, implementado pela Lei Rouanet, no plano federal e a lei estadual de incentivo à cultura.
} 


\section{Universidade do Extremo Sul Catarinense \\ Revista lbero-Americana de Humanidades, Ciências e \\ Educação \\ unesc

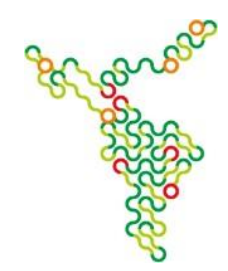

deslocamento das representações acerca da ideia de nação, apresentaremos cinco enredos ${ }^{6}$ que a partir da década de 1990, explicitam simbolicamente o Brasil a partir desta nova lógica fragmentada, regionalizada, multicultural, enfim, micro:1992 - Paulicéia desvairada, 70 anos de modernismo no Brasil (Estácio); 1997 - Cidade maravilhosa, o sonho de Pereira Passos (União da Ilha); 1998 - O mundo místico dos Caruanas nas águas do Patu-Anu. (Beija flor); 2002 - Brazil com Z é pra cabra da peste, Brasil com S é nação do Nordeste. (Mangueira); 2013 - “A Vila canta o Brasil celeiro do mundo - Água no feijão que chegou mais um..."(Vila Isabel);

\section{Referências}

ANDERSON, Benedict. Comunidades imaginadas: reflexões sobre a origem e a difusão do nacionalismo. São Paulo: Cia. das Letras, 2008.

AUGRAS, Monique. O Brasil do samba enredo. Rio de Janeiro: FGV, 1998. BHABHA, Homi. O local da cultura. Belo Horizonte: Editora UFMG, 1998.

CANCLINI, Nestor Garcia. Consumidores e Cidadãos: conflitos multiculturais da globalização. 4. ed. Rio de Janeiro: UFRJ, 1999.

CANDIDO, Antonio. A dialética da malandragem. São Paulo: Revista do Instituto de Estudos Brasileiros, 1970.

CAVALCANTI, Maria Laura Viveiros de Castro. Carnaval Carioca dos Bastidores ao Desfile. Rio de Janeiro: FUNARTE/UFRJ, 1994.

CHINELLI, Filippina \& SILVA, Luís Antônio Machado da. O vazio da ordem: relações políticas e organizacionais entre escolas de samba e o jogo do bicho. Boletim do Laboratório de Pesquisa Social n 2. Rio de Janeiro: IFCS/UFRJ, 1991. CLIFFORD, James. A experiência etnográfica: Antropologia e literatura no século XX. Rio de Janeiro: UFRJ, 1998.

CUNHA, Maria Clementina P. Ecos da Folia: Uma História Social do Carnaval Carioca entre 1880 e 1920. São Paulo: Cia. Das Letras. 2001

CUNHA, Milton. O Brasil é um luxo: 30 carnavais de Joãozinho Trinta. São Paulo: CBPC, 2008.

DINIZ, Júlio Cesar Valladão et al. (ORG.). Leituras sobre música popular: reflexões sobre sonoridade e cultura. Rio de janeiro: 7letras, 2008.

FARIAS, Júlio César. O enredo de escola de samba. Rio de Janeiro: Letteris, 2007. GOMES, Antonio Henrique de Castilho. A [re]configuração do discurso do samba.

\footnotetext{
${ }^{6}$ Caso o leitor deseje ver mais exemplos sugiro o acesso ao site da LIESA: http://liesa.globo.com
} 


\section{Universidade do Extremo Sul Catarinense \\ Revista Ibero-Americana de Humanidades, Ciências e \\ Educação \\ Unesc Produção e democratização do conhecimento na lbero-América}

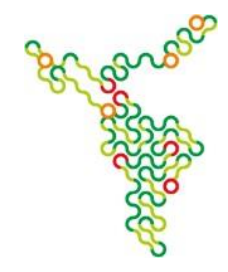

Curitiba: CRV, 2014.

GONÇALVES, Renata. Os ranchos pedem passagem. Rio de Janeiro, Prefeitura do

Rio/Culturas. Col. Biblioteca Carioca, 2007.

GUHA, Ranajit. On some aspects of the historiography of colonial India. Subaltern Studies 1: Writings on South Asian history and society. Delhi: OUP, 1982.

HALL, Stuart. A identidade cultural na pós-modernidade. Rio de Janeiro: DP\&A, 2005.

História das escolas de samba. São Paulo: O Globo, vol. 3, 1976.

MATOS, Cláudia. Acertei no Milhar: samba e malandragem no tempo de Getúlio. Rio de Janeiro: Paz e Terra, 1981.

MEMÓRIA DO CARNAVAL. Riotur, 1991.

MIRANDA, Dilmar. "Carnavalização e Multidentidade cultural: antropofagia e tropicalismo". In: Tempo Social (Revista de sociologia da USP). São Paulo: USP, Outubro de 1997.

MORIN, Edgar. Meus Demônios. São Paulo: Bertrand, 1997.

MOURA, Roberto Murcia.. Tia Ciata e a Pequena África no Rio de Janeiro. Rio de Janeiro: Sec. Mun. De Cultura, Dep. Geral de Doc. E Inf. Cultural, Divisão de Editoração, 1995.

MUSSA, Alberto; SIMAS Luiz Antonio. Sambas de enredo: história e arte. Rio de Janeiro: Civilização Brasileira, 2010.

RIO, João do Rio. A alma encantadora das ruas. São Paulo: Cia. Das Letras, 2008.

ROCHA, João Cezar de Castro. Dialética da Marginalidade. Caderno Mais. Folha de São Paulo: Fevereiro/2004.

SANDRONI, Carlos. Feitiço Decente: transformações no samba do Rio de Janeiro (1917/1933). Rio de Janeiro: Jorge Zahar Ed. 2001.

SODRÉ, Muniz. Samba o Dono do Corpo. Rio de Janeiro: Mauad, 1998.

SOUZA, Cássia Helena Glioche Novelli de.; SCHMIDT, Beatriz . O desfile das escolas de samba na televisão: vinte anos de sambódromo. Monografia apresentada como exigência parcial do Curso de Comunicação Social da Universidade Estácio de Sá Habilitação Jornalismo. Rio de Janeiro:Dezembro/2004.

VALENÇA, Raquel Teixeira. Carnaval: para tudo se acabar na quarta-feira. Rio de 


\section{Universidade do Extremo Sul Catarinense}

Revista Ibero-Americana de Humanidades, Ciências e

Educação

UnesC Produção e democratização do conhecimento na lbero-América

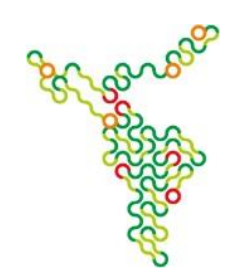

Janeiro: Relume-Dumara/ Prefeitura, 1996. (Arenas do Rio; 3)

VIANA, Hermano. O Mistério do Samba. Rio de Janeiro: Jorge Zahar/UFRJ, 1995.

AUGRAS, Monique. A ordem na desordem: a regulamentação dos desfiles das escolas de samba e a exigência de "motivos nacionais". Disponível em:

http://www.anpocs.org.br. Acesso em 20 de set de 2017.

HARTMANN, Érica de Oliveira e BORGES, Guilherme Roman. A globalização e o estado- nação: rumo à pós-modernidade e ao estado cosmopolita? Disponível em: http://revistas.ufpr.br. Acesso em 01 de set de 2017.

LOPES, Carla Alves; MALAFAIA, Maria Cecília Tavares; VINHAIS, José Carlos. Administração em escolas de samba: os bastidores do sucesso do carnaval carioca. Disponível em: www.aedb.br/seget. Acesso em 15 de out de 2016.

Pamplona, o revolucionário tradicional. Entrevista concedida a Bruno Filippo. Disponível em: www.odiaonline.com.br. Acesso em 01 de set de 2017.

PRESTES FILHO, Luiz Carlos et al. Cadeia produtiva da economia do carnaval. Disponível em: www.fundaj.gov.br. Acesso em 11 de mar de 2016. 